\section{Commentary: Learning from past mistakes - a detailed hybrid approach to mitral annular calcification}

\author{
Stephanie Tom, MD, and \\ Kendra J. Grubb, MD, MHA, FACC ${ }^{b}$
}

The treatment of mitral valve disease in the setting of severe mitral annular calcification (MAC) remains a surgical challenge. Traditional cardiac surgical approaches for MAC have been fraught with several well-described complications revolving around the need for annular debridement with the feared risk of atrioventricular disruption. Moreover, these patients tend to be older, with multiple comorbidities, placing them in the high-risk stratification group, and thus many are denied surgery. ${ }^{1}$

Valve in MAC (Vi-MAC) is an off-label technique that has been developed to address this challenge. Initially described as a transapical approach with a minithoracotomy, Vi-MAC is now most often accomplished via a transseptal technique with the SAPIEN 3 (Edwards Lifesciences, Irvine, Calif) device. ${ }^{2}$ The valve, designed for transcatheter aortic valve replacement (TAVR), is loaded onto the balloon opposite that for a retrograde transfemoral TAVR, and the delivery system is introduced into the femoral vein turned $180^{\circ}$ to leverage the steering mechanism of the SAPIEN 3 delivery system. The transseptal approach is feasible but challenging, as proper positioning of the guidewire in the ventricle often fails to achieve coaxial alignment with the mitral annulus and can result in paravalvular leak (PVL), valve migration, or embolization. ${ }^{2}$ This has led to adjuncts, such as the Emory Angle, to predict

From the ${ }^{\mathrm{a}}$ Department of Surgery, and ${ }^{\mathrm{b}}$ Division of Cardiothoracic Surgery, Structural Heart and Valve Center, Emory University, Atlanta, Ga.

Disclosures: Dr Grubb is a consultant for Medtronic and Edwards Lifesciences. Dr Tom reported no conflicts of interest.

The Journal policy requires editors and reviewers to disclose conflicts of interest and to decline handling or reviewing manuscripts for which they may have a conflict of interest. The editors and reviewers of this article have no conflicts of interest.

Received for publication July 8, 2021; revisions received July 8, 2021; accepted for publication July 16, 2021; available ahead of print July 21, 2021.

Address for reprints: Kendra J. Grubb, MD, MHA, FACC, Division of Cardiovascular Surgery, Structural Heart and Valve Center, Emory University School of Medicine, 550 Peachtree St NE, Davis-Fischer, Atlanta, GA 30308 (E-mail: kjgrubb@emory. edu).

JTCVS Techniques 2021;9:57-8

2666-2507

Copyright (C) 2021 The Author(s). Published by Elsevier Inc. on behalf of The American Association for Thoracic Surgery. This is an open access article under the CC BY-NC-ND license (http://creativecommons.org/licenses/by-nc-nd/4.0/).

https://doi.org/10.1016/j.xjtc.2021.07.013

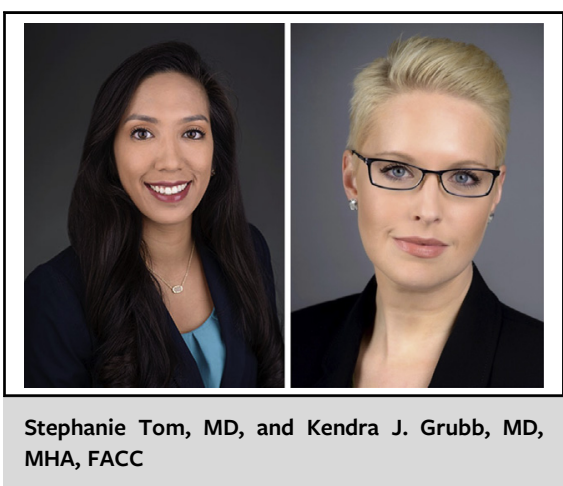

CENTRAL MESSAGE

MAC is challenging surgically, with limited transcatheter options.

Leveraging surgical principles and hybrid techniques mitigate complications and offer treatment for high-risk patients.

valve canting, and externalization of the wire via an apical rail. $^{3}$ Moreover, patients who undergo Vi-MAC are at increased risk of left ventricular outflow tract obstruction from displacement of the anterior mitral leaflet by the TAVR valve frame. ${ }^{2}$ This devastating complication limits the utility of Vi-MAC but can be overcome with an advanced electrosurgical technique to split the anterior leaflet termed LAMPOON. ${ }^{4}$ Considering the technical complexity, percutaneous Vi-MAC should be reserved for the most experienced operators.

In this edition of JTCVS Techniques, Kawano and colleagues ${ }^{5}$ presented a case series of 11 patients who underwent a hybrid transatrial mitral valve replacement with the SAPIEN 3 device deployed under direct vision. The surgeons leveraged surgical principles, including minimal annular debridement and selective annular suturing, to mitigate complications and facilitate proper positioning. Further, they fashioned an external skirt around the balloonexpandable SAPIEN 3 valve to enhance sealing and reduce PVL. The concept presented is not novel, but the authors present a valuable technique with details to make the procedure accessible to a broad range of surgical teams.

In their high-risk (Society of Thoracic Surgeons Predicted Risk of Mortality $9.73 \%$ ) elderly patient population, mean age 75 years, the authors had no reported in-hospital or 30 -day deaths, and technical success was achieved in $90 \%$ of cases, ${ }^{5}$ the caveat being that the patients were selected who could withstand open cardiac surgery. The described hybrid approach, leveraging open surgical techniques under 
cardiopulmonary bypass, removal of the anterior mitral leaflet to avoid left ventricular outflow tract obstruction, and deployment of the valve under direct vision to mitigate the risk of PVL, demonstrates a reproducible approach to the treatment of mitral valve disease with concomitant MAC. The technique described offers yet another option for this challenging high-risk patient population.

\section{References}

1. Abramowitz Y, Jilaihawi H, Chakravarty T, Mack MJ, Makkar RR. Mitral annulus calcification. J Am Coll Cardiol. 2015;66:1934-41.
2. Guerrero M, Urena M, Himbert D, Wang DD, Eleid M, Kodali S, et al. 1-year outcomes of transcatheter mitral valve replacement in patients with severe mitral annular calcification. J Am Coll Cardiol. 2018;71:1841-53.

3. Greenbaum A, Lisko JC, Gleasson PT, Kamioka N, Metcalf DP, Greenbaum MA, et al. Annular-to-apical "Emory angle" to ensure coaxial mitral implantation of thee SAPIEN 3 valve. JACC Cardiovasc Interv. 2020;13: 2447-50.

4. Khan JM, Babaliaros VC, Greenbaum AB, Foerst JR, Yazdani S, McCabe JM, et al. Anterior leaflet laceration to prevent ventricular outflow tract obstruction during transcatheter mitral valve replacement. J Am Coll Cardiol. 2019;73: 2521-34.

5. Kawano Y, Newell P, Harloff M, Hirji S, Percy E, Shah P, et al. Early outcomes of trans-atrial mitral valve replacement in severe mitral annular calcification. $J$ Thorac Cardiovasc Surg Tech. 2021;9:49-56. 